\title{
La ciencia política en El Salvador: SUS PRIMEROS PASOS
}

\author{
Álvaro Artiga-González \\ Universidad Centroamericana José Simeón Cañas, El Salvador
}

\begin{abstract}
Resumen
En este trabajo se hace una descripción del más reciente desarrollo de la ciencia política en El Salvador. Se presentan sus orígenes, evolución, influencias académicas recibidas, desafíos, fortalezas, salidas laborales de los egresados de esta disciplina, su valoración social y su impacto. Al año 2005, en El Salvador solamente existe un programa académico de ciencia política. Éste funciona a nivel de estudios de maestría. Por esta razón la perspectiva adoptada para la descripción es más específica que general. Por otra parte, la investigación todavía es incipiente. La comunidad de politólogos salvadoreños tiene pocos miembros, todos con formación en el extranjero y representan, en cierta forma, una generación de relevo en las ciencias sociales salvadoreñas.
\end{abstract}

\begin{abstract}
In this paper, a description of the most recent development of political science in El Salvador is drawn. Its origins, evolution, academic influences, challenges, strengths, social appraisal, impacts and the job opportunities for the new professionals graduated from this discipline are briefly described. The paper emphasizes three points: First, the fact that only one Political Science Academic Program exists in El Salvador, a Master's Degree Program. This article mostly refers to this Program and, therefore, has a specific focus rather than a general one. Second, political science research is also still at its beginning stages. Finally, the Community of Salvadoran scholars in political science is small. In fact, it only has a few members, less than ten. They all graduated from foreign universities, and represent in someway a generational chance for the social sciences in El Salvador.
\end{abstract}

\section{PALABRAS CLAVE • Ciencia Política • El Salvador • Disciplina • Investigación}

\section{LOS ORÍGENES DE LA CIENCIA POLÍTICA EN EL SALVADOR}

Rigurosamente hablando, la ciencia política en El Salvador es un área del conocimiento con existencia muy reciente. Puede datarse a partir de mediados de la década de los años 90 . Esto no quiere decir que antes no se hicieran estudios políticos o que los objetos de estudio de la ciencia política no fuesen abordados desde la academia. Podría decirse incluso que hubo un primer intento de desarrollar esta ciencia en la Universidad Centroamericana J osé Simeón Cañas (UCA) de EI Salvador en la década de los años setenta puesto que se abrió la licenciatura en ciencias políticas. Pero las condiciones sociopolíticas por las que atravesaba el país truncaron la experiencia en 1979 cuando un golpe de Estado dio pie a la formación de un gobierno en el que tomaron parte varios de los docentes de la UCA que tenían participación en aquella licenciatura. El fracaso de aquel gobierno para detener la represión y persecución política que venía caracterizando al país desde 1975 hizo que aquellos docentes salieran al exilio y la carrera fuera cerrada.

Posteriormente, ya en la década de los años ochenta, la misma universidad abrió la carrera de sociología y desde ésta fueron abordados los objetos de estudio de la ciencia política, además de 
los propios de la sociología. Este desarrollo era convergente con el que venía realizándose desde la Universidad de El Salvador (UES, única universidad estatal) en la Facultad de Jurisprudencia y Ciencias Sociales. Quienes estudiaban Derecho recibían nociones de teoría del estado y quienes estudiaban sociología abordaban temas políticos en una especie de sociología política, de corte estructuralista y muy impregnada de marxismo. Otra aproximación a la política se llevaba a cabo desde la carrera de Relaciones Internacionales en la UES.

Como en otros contextos autoritarios de América Latina, la carrera de sociología en El Salvador tuvo un carácter conscientemente comprometido con la sociedad. Tanto la UES como la UCA se pensaban como agentes del cambio social (Mayorga Quirós, 1976). Ello tuvo sus efectos en los problemas abordados y los enfoques adoptados. La sociología en estas dos universidades - las únicas en las que se ofertaba la carrera en el país- estaba influenciada por los autores, o bien marxistas, o bien dependentistas. Marxismo y Teoría de la Dependencia constituían su soporte teórico fundamental aunque no exclusivo.

La década de los años 80 es la década de la guerra civil en El Salvador. Ello tuvo su impacto en los problemas abordados desde la Academia e incluso en las condiciones en que se desarrollaba la sociología. La sospecha gubernamental sobre la literatura sociológica (o de las ciencias sociales en general) impuso límites a la actualización bibliográfica e hizo que las bibliotecas, editoriales y librerías del país tuviesen una escasa oferta de textos. El recurso a las fotocopias alivió un poco esta carencia. El conflicto armado en El Salvador finalizó con la firma de Acuerdos de Paz entre el Gobierno salvadoreño y la guerrilla del Frente Farabundo Martí para la Liberación Nacional (FMLN), en enero de 1992. Tales acuerdos significaron, entre otras cosas, la instauración de un nuevo régimen político y tendrían un impacto directo sobre la academia pues, desde entonces, la literatura que antes era sospechosa dejó de serlo. En este sentido, la Academia comenzó a gozar de un mayor margen de libertad de expresión. Sin embargo, el peso de las reformas económicas neoliberales implementadas desde el primer gobierno del partido Alianza Republicana Nacionalista (ARENA), 1989-1994, representaron un nuevo desafío para el desarrollo de las ciencias sociales en el país. Los criterios de mercado (viabilidad económica de la oferta académica) comenzaron a tener un mayor peso dentro de las universidades y centros de investigación. Sin que haya sido un objetivo de aquellas reformas, las universidades comenzaron a preguntarse por la rentabilidad de las carreras que ofrecían. En este contexto, la carrera de sociología fue cerrada (junto a otras) en la UCA, aunque el departamento que la impartía siguió sirviendo asignaturas de las ciencias sociales a otras carreras y departamentos. La sociología en la UES se benefició parcialmente de esta decisión, pues recibiría una mayor demanda estudiantil. En todo caso esta demanda no sobrepasaría el centenar.

En el contexto de la apertura política una nueva oferta de ciencia política ve la luz en el país. La Universidad Tecnológica de El Salvador (UTEC, universidad privada) implementa un Programa de Maestría en Ciencia Política que, sin embargo, pronto sería cerrado por falta de alumnos y dudas sobre su calidad. Una cuarta universidad, la Universidad Nueva San Salvador (UNSSA, también privada) abre una licenciatura en ciencias políticas en la década de los años 90 . En este caso se trata de una universidad pequeña sin mayor relevancia en el ámbito académico nacional.

En la década de los años 90, la UCA se embarca en un proceso de desarrollo institucional que implicaba, entre otras cosas, la apertura de programas de postgrado. Hacia el año 2000 planifica 
un Programa de Maestría en Ciencia Política que sería ofertado a partir de 2001. Había pasado una década desde la firma de los Acuerdos de Paz y los desafíos que implicaban la democratización del nuevo régimen habían salido a flote junto con aquellos que, como legados del régimen autoritario, comenzaban a notarse con mayor claridad. La práctica de la democracia en El Salvador no partía de cero, sino de las viejas prácticas políticas autoritarias. La discusión y la negociación entre actores con diversos intereses sobre las políticas a seguir no era una característica del modo de hacer política en El Salvador y, sin embargo, se consideraba necesaria para el ejercicio del buen gobierno. En la medida en que la democracia no había constituido objetivo primordial de los principales actores políticos que, por la vía armada y la negociación política, propiciaron la instauración de un nuevo régimen, la cualidad democrática de éste no estaba asegurada. La democratización del régimen político necesitaba demócratas que la impulsaran. La formación de los mismos fue una tarea que la UCA consideró urgente e imprescindible y la asumió como premisa para crear su nuevo Programa de Ciencia Política. Así, intentaba influir, una vez más, sobre la realidad política nacional. Además, había que ir contra la apatía y la falta de interés ciudadano en la política, por lo menos, para evitar una regresión autoritaria.

Por otro lado, cambios económicos y sociales de gran envergadura y sus consecuencias en el largo plazo están en marcha en los ámbitos nacional y mundial. Esto implicaría que temas como la reforma del Estado -modernización, privatización, descentralización, etc.-- la desigualdad y la pobreza, la vivienda, la salud, la reactivación del agro, la creación de empleo, el deterioro del medio ambiente, la seguridad pública, la violencia social - pública e intrafamiliar-, el desarrollo local, el municipalismo, la participación ciudadana, la educación, etc., entraran a formar parte de las preocupaciones de investigación de la nueva ciencia política en El Salvador, junto a los temas ya "clásicos" del cambio de régimen y la consolidación democrática.

Los cambios producidos en el país en el cambio de siglo pusieron sobre la mesa la necesidad que tiene el país de contar con recursos humanos capaces no sólo de formular racionalmente políticas, sino que éstas sean eficaces por sus resultados y por su contribución a la consolidación de un régimen democrático en El Salvador. Tales recursos humanos no deben identificarse con los políticos profesionales únicamente. Debe incluirse también los asesores, los negociadores, los analistas y líderes de opinión, entre otros. En fin todo aquel agente cuyo trabajo busca incidir en el manejo de "la cosa pública". La formación de estos recursos humanos fue un desafío que asumió en 2001 la UCA como parte de su quehacer universitario en la nueva etapa del proceso político salvadoreño. Así es como se diseña e implanta un Programa de Maestría en Ciencia Política, el segundo a nivel de la región centroamericana ${ }^{1}$. En sus inicios esta escasez de programas de postgrado en ciencia política en la región expresa a la vez la aus encia de profesionales graduados dedicados a la enseñanza y la investigación en toda la región. Esta situación hace que el mencionado programa se encuentre en un ambiente prácticamente virgen, con muchos problemas que investigar y escasos recursos dedicados a tal fin. 


\section{PREGUNTAS Y RESPUESTAS DE INVESTIGACIÓN}

La nueva Ciencia Política de la UCA nace con un claro sesgo institucionalista. Influido por una abundante literatura politológica que se preocupa por el cambio de régimen (o transiciones desde regímenes autoritarios) y la consolidación de la democracia, las preguntas con las que comienza su andadura son aquellas que tienen que ver con el diseño institucional y su rendimiento. Las preguntas por la morfología y génesis de los sistemas de partidos, los efectos de los sistemas electorales sobre los sistemas de partidos, los condicionantes del comportamiento electoral aparecen en la primera línea de la agenda temática de investigación (por ejemplo, Artiga-González, 2004). Sin embargo, la ciencia política de la UCA se plantea para su posterior desarrollo siete ejes temáticos de investigación: instituciones políticas, actores políticos, cultura política, política comparada ${ }^{2}$, políticas sociales, política económica y política internacional.

A cinco años de la existencia del programa, esta agenda es más bien un horizonte por el cual avanzar. Antes debe consolidar el área docente y allí el problema principal que enfrenta es el de la formación de los profesores e investigadores. La colaboración interuniversitaria y a título personal ha sido fundamental para el desarrollo del programa. Universidades de la región centroamericana en las que existen politólogos cooperan con el Programa de Ciencia Política de la UCA. A nivel personal, motivados por vínculos de amistad y deseo de cooperar en la institucionalización de la ciencia política en El Salvador, profesores de universidades de España -en concreto de Salamanca y Barcelona- han impartido algunas clases en un par de universidades salvadoreñas, incluyendo la UCA.

\section{DIFERENCIAS INTERNAS MÁS IMPORTANTES DENTRO DEL ÁMBITO DE LA POLITOLOGÍA SALVADOREÑA}

Al existir un único programa de estudios en ciencia política a nivel de postgrado, y ser además muy reciente, todavía no han salido a flote diferencias importantes. Sin embargo, la existencia de un único programa no debe entenderse como monopolio en la producción de estudios y conocimiento politológico. Fuera de la UCA hay otros politólogos que se desempeñan como consultores independientes o trabajan para think tanks. Se trata de un reducido número de investigadores, no son más de diez. Incluso el número se reduce más aún si se cuentan solo los doctores en ciencia política, puesto que en ese caso no son más de cinco. Todos ellos graduados fuera del país, algunos en Estados Unidos y otros en México o España. En la medida en que los programas de doctorado de estos dos últimos países han recibido una influencia anglosajona importante en las últimas décadas, se puede afirmar que existe una cierta homogeneidad en la formación de los doctores en ciencia política salvadoreños.

La situación planteada en el párrafo anterior significa un cambio importante para los estudios de ciencia política en El Salvador. En primer lugar, ahora la producción de conocimiento politológico es llevado a cabo por politólogos de formación. Ello no quiere decir que otros profesionales de las ciencias sociales que estudiaban objetos políticos ya no lo hagan ${ }^{3}$. Más bien significa, en segundo

2 Este eje de investigación se ve favorecido por la participación de docentes del programa en investigaciones colectivas internacionales coordinadas en red (Ver Alcántara y Freidenberg, 2001; CAPEL, 2004; Martínez, 2004; Rovira Mas, 2001)

3 Es el caso de los filósofos, sociólogos y psicólogos sociales (ver Artiga-González et al., 2002; Cardenal y González, 2002; Cruz, 2001; Guido Béjar y Roggenbuck, 1996 y Santacruz Giralt, 2003) 
lugar, que ahora existe en el país una competencia entre académicos de las ciencias sociales para redefinir los ámbitos disciplinarios de tal manera que la ciencia política tenga el suyo propio. La existencia del programa de postgrado en la UCA va definiendo ese espacio de manera institucional. Es de esperar que en los años venideros alguna otra universidad implemente algún otro programa afín para romper el monopolio que hoy tiene la UCA. En tercer lugar, el reducido número de doctores en ciencia política en El Salvador ha obligado a la especialización temática. Así, tenemos especialistas en seguridad y política global, cultura política y opinión pública, partidos y sistemas de partidos, sistemas electorales y modernización del Estado. Finalmente, la delimitación del espacio académico para la ciencia política ha supuesto una competencia particularmente con los sociólogos. Aquí hay incluso una disputa en términos generacionales y de enfoques. La sociología salvadoreña siempre tuvo una mayor inspiración latinoamericanista, influida por la sociología europea continental (especialmente de Francia y Alemania). Por tanto, siempre fue una sociología más de corte interpretativo. La ciencia política salvadoreña en el nuevo siglo nace más bien influenciada por la perspectiva anglosajona, de corte más empírico y probablemente con un sesgo más cuantitativista ${ }^{4}$.

Pese a las diferencias señaladas, el compromiso explícito de poner el conocimiento al servicio del cambio social es compartido por ambos grupos de científicos sociales y permite el diálogo interdisciplinario e incluso la colaboración de los sociólogos salvadoreños al desarrollo de la ciencia política en el país. Ello se manifiesta en la participación de sociólogos como docentes en algunas asignaturas del programa de ciencia política de la UCA.

\section{MAYORES DESAFÍOS DE LA CIENCIA POLÍTICA EN EL SALVADOR}

Es evidente que el mayor desafío que tiene la ciencia política en El Salvador es la reproducción de los profesionales que la practican, especialmente los doctores en la disciplina. Como se ha mencionado por ahora el país cuenta con un reducido grupo. Sólo uno de ellos está contratado a tiempo completo en una universidad. El resto, aunque eventualmente, ejerce funciones docentes, se dedica más bien a la consultoría. Los graduados del programa de maestría de ciencia política de la UCA todavía constituyen un pequeño grupo. Antes que contribuir al desarrollo de la disciplina, la inmensa mayoría sigue dedicada al campo profesional al que pertenecían antes de realizar sus estudios de postgrado.

Por otra parte, todavía no existen revistas especializadas de ciencia política en El Salvador ni parece que ésta sea una prioridad entre los politólogos salvadoreños ${ }^{5}$. En realidad este es un fenómeno que se registra en otras disciplinas ya consolidadas en el país como la medicina, la psicología, la sociología y el derecho. Los profesionales de estas disciplinas dan a conocer sus trabajos a través de revistas de corte más general producidas en algunas universidades locales, públicas o privadas. Los "documentos de trabajo" editados por FLACSO-Programa El Salvador han sido otra alternativa de difusión, aunque de escasa circulación y dirigidos a un público heterogéneo. De hecho, FLACSO-Programa El Salvador no cuenta con politólogo alguno entre su staff

$4 \quad$ Lo cual no significa que no haya interés por la teoría y por lo cualitativo. Simplemente quiere decir que se privilegia más la explicación que la interpretación.

5 Lo cual no quiere decir que estos politólogos no publiquen sus trabajos, su producción intelectual. Para ello se valen de otras revistas de ciencias sociales que circulan en el país o bien los divulgan a través de informes de consultorías encomendadas por agencias internacionales. En algunos casos, la producción de estos politólogos circula más bien a nivel internacional en revistas españolas, sur y centroamericanas. El acceso a revistas en inglés es todavía muy escaso. 
pese a estar participando en la formación de jóvenes investigadores a nivel de postgrado centroamericano junto a las sedes académicas de Guatemala y Costa Rica.

Un tercer desafío para la ciencia política salvadoreña viene por el lado de la producción científica. Siendo una disciplina con pocos años de existencia, además de ganarse su propio espacio en la academia, debe pelear por otro entre las agencias que apoyan la investigación. Los politólogos dedicados al estudio de la cultura política han avanzado bastante en este sentido pues este campo ha encontrado apoyo en agencias de cooperación europeas y estadounidenses. Las encuestas de opinión son las que han recibido el mayor apoyo. En este sentido es importante mencionar que son dos centros los que más encuestas de opinión sobre temas políticos hacen en El Salvador: la Fundación Dr. Guillermo Manuel Ungo (FundaUngo) y el Instituto Universitario de Opinión Pública (IUDOP) de la UCA. Ambas instituciones, y sus investigadores, participan en una red de centros de investigación coordinados por la Universidad de Vanderbilt, en Estados Unidos ${ }^{6}$.

\section{PRINCIPALES FORTALEZAS ACTUALES DE LA CIENCIA POLÍTICA EN EL SALVADOR}

Probablemente tres son las mayores fortalezas de la ciencia política salvadoreña en este momento. Por un lado, se está desarrollando en un medio en el que se demanda conocimiento técnico y científico desde las organizaciones estatales y sociales. No solamente en términos de consultorías, sino también como necesidad de formación de cuadros. En cierta forma, el (re)surgimiento de la ciencia política en El Salvador ha ido acompañando los desafíos que el nuevo régimen político salvadoreño ha tenido que ir enfrentando desde su instauración en la década de los años noventa. En este sentido, la disciplina ha encontrado un terreno favorable para su desarrollo.

En segundo lugar, los pocos politólogos salvadoreños fueron formados (hicieron sus doctorados) fuera del país y lograron establecer redes y vínculos académicos que ahora están aprovechando para mantenerse actualizados, pero también para dar a conocer su producción. Desde este punto de vista la conexión de la ciencia política nacional con las redes académicas internacionales es una condición de partida favorable para el desarrollo de la disciplina en el país. Los politólogos salvadoreños se ven así fortalecidos, porque no se sienten solos como de otra manera lo estarían dado su número reducido en el país. Es importante hacer notar que algunos de ellos incluso son profesores invitados en universidades fuera del país (en Estados Unidos y España), lo cual les mantiene en permanente actualización.

En tercer lugar, como se trata de un grupo reducido de politólogos con cierta especialización temática, por de pronto no han surgido divisiones ni conflictos en su interior que les signifique algún tipo de desgaste intelectual. Las relaciones entre ellos son más bien personales antes que institucionales. Ello favorece un clima de cooperación entre las organizaciones de las que forman parte.

La última publicación de esta red fue presentada en abril del presente año (Córdova Macías y Cruz, 2005) y es parte de un proyecto sobre cultura política democrática realizado en ocho países que incluyen México, Centroamérica, Panamá y Colombia. Los informes (nacionales y regionales) pueden consultarse en Internet. 


\section{SALIDAS LABORALES MÁS COMUNES DE LOS EGRESADOS DE LA DISCIPLINA}

Por las características del todavía único programa de formación a nivel de postgrado en ciencia política que lleva a cabo la UCA y, dado que es muy reciente su implementación, las salidas laborales de sus egresados siguen siendo más bien aquellas desde las que ingresaron al programa. Sus estudiantes provienen en su mayoría del sector público -ministerios y entidades del sector justicia- y profesionalmente constituyen un grupo heterogéneo en el cual puede encontrarse: abogados, comunicadores sociales, sociólogos, economistas, psicólogos, médicos, ingenieros y egresados de relaciones internacionales. Por supuesto, la tendencia en la integración de las hasta ahora cuatro promociones ha sido la de tener una cuota mayoritaria de abogados (prácticamente el $50 \%$ de los estudiantes matriculados en cada promoción). Como fenómeno digno de hacer notar es la creciente participación de alumnos provenientes del campo de las comunicaciones y el periodismo.

El programa de ciencia política de la UCA se autofinancia fundamentalmente a partir de las cuotas que pagan los estudiantes. Todavía no se cuenta con un apoyo en términos de becas (completas o parciales), lo cual exige que los aspirantes al programa tengan, o bien apoyo familiar para financiarse los estudios, o bien un empleo estable con cuyo salario puedan cubrir sus estudios. Esta segunda situación es la que se presenta con más frecuencia, razón por la cual el programa se desarrolla en horarios vespertinos. Esto tiene sus ventajas y desventajas. Entre las primeras, es un programa al que pueden optar personas empleadas en oficinas públicas o privadas cuya expectativa al graduarse es mejorar su estatus laboral dentro de las mismas oficinas. Entre las desventajas está el hecho de tener que contar casi en su totalidad con estudiantes a tiempo parcial con limitaciones incluso para visitar bibliotecas y ejercitarse en la investigación de campo (puesto que en las horas en que podrían llevar a cabo este programa están trabajando en sus respectivas oficinas).

\section{VALORACIÓN SOCIAL DE LA CIENCIA POLÍTICA EN EL SALVADOR}

Al hablar de ciencia política en el país la primera imagen que viene a la mente de muchas personas es la de una actividad que llevan a cabo los políticos 0 , por lo menos, que se trata de unos estudios para preparar a los políticos. Hasta cierto punto esta es una situación normal si se toma en cuenta que socialmente más bien lo que hay es un desconocimiento de la existencia misma de la ciencia política. Y que pueden existir personas que sin dedicarse a la política (como funcionarios públicos o miembros de partidos políticos) adquieran o posean conocimientos políticos. Este desconocimiento favorece el traslado del estigma social que tienen la política, como algo sucio, y los políticos, como gente corrupta, a la ciencia política y a los politólogos. Sin embargo, al presentarse esta disciplina como actividad racional y en la medida en que socialmente se va dando a conocer su producción, aquel estigma va cediendo espacio a una valoración positiva: como una actividad necesaria para formar una nueva generación de políticos y funcionarios públicos que se desempeñen con un conocimiento que es percibido como necesario para su profesionalización.

En el desarrollo de una percepción social de necesidad de la ciencia política contribuye el desempeño de los politólogos como formadores de opinión al ser entrevistados en diversos medios de radio, prensa y televisión. Esta situación favorable se acentúa en los contextos preelectorales 
cuando se les llama para ser entrevistados sobre los temas de la coyuntura. Todavía es muy temprano para afirmar que existe una clara distinción social entre lo que son politólogos y políticos, pero la institucionalización de la disciplina apunta hacia ella.

\section{LA PREGUNTA POR EL IMPACTO DE LA DISCIPLINA EN EL MEDIO}

Es difícil poder hablar con propiedad del impacto que la ciencia política tiene en El Salvador puesto que su último desarrollo apenas es incipiente. Algo podría intuirse a partir de dos tipos de actividades en las que se ven inmersos los politólogos: a) divulgación de su producción intelectual, y b) realización de foros de discusión. El primer tipo de actividad se refiere a la presentación pública de trabajos de investigación, normalmente auspiciados por alguna agencia de cooperación. Al dirigirse a un público que desborda la disciplina, lo que busca es influir en las opiniones que aquél tiene sobre los temas investigados y que tienen alguna relevancia social. En algunos casos, la divulgación se hace ante públicos muy específicos, como por ejemplo una comisión legislativa. En todo caso su finalidad es influir en las percepciones y opiniones que diversos actores estratégicos tienen sobre algún tema político relevante y, normalmente, de carácter coyuntural.

El segundo tipo de actividades también se dirige a la influencia en la opinión pública, pero la arena es distinta. Si en el caso anterior el público suele tener algún nivel de especialización profesional, en este caso el público es más heterogéneo. Se trata de actividades abiertas al público en general llevadas a cabo unas veces en recintos universitarios, otras en hoteles, dependiendo de quién es el que organiza la actividad (foro, panel, mesa redonda, etc.). El acceso a los medios de comunicación masiva, especialmente la televisión, vuelve aún más heterogéneo el público e incrementa la probabilidad de tener alguna incidencia política de los politólogos.

Por otra parte, al examinar con más detalle el programa de postgrado en ciencia política de la UCA salta a la vista lo que probablemente sea uno de los impactos a mediano y largo plazo de la politología en El Salvador. Se está preparando una nueva generación de agentes políticos. Esto ocurre por dos medios: los cursos formales del programa de postgrado y los cursos de extensión (abiertos). A través de los primeros se preparan recursos humanos con algún nivel de especialización en el tratamiento de asuntos políticos. A la vez, con la colaboración de los docentes extranjeros invitados a impartir cursos del programa, la formación impartida a los maestrandos tiene un carácter actual. Por este medio el flujo de nuevas ideas y perspectivas de análisis ha encontrado un canal institucional académico efectivo.

El postgrado en ciencia política de la UCA cuenta con un programa radial, con cobertura nacional a través de la radio YSUCA que le permite acceder a un público aun mayor y diverso. Con línea telefónica abierta, docentes y alumnos de la maestría en ciencia política de la UCA entran en contacto con la audiencia formando una especie de comunidad radio hablante. El aula universitaria es convertida en una sala radial donde son tratados temas políticos de interés coyuntural y donde los estudiantes del postgrado, que están en proceso de elaboración de su tesis de maestría, dan a conocer y discuten en lenguaje coloquial avances de su trabajo. Esta interacción radial hace que la ciencia política salvadoreña permanezca "anclada" a los asuntos que son socialmente pertinentes y relevantes.

Quizá el mayor impacto que llegue a tener la ciencia política en El Salvador se produzca en la racionalización del debate político. No tanto porque entre los futuros políticos salvadoreños hayan 
algunos politólogos, sino porque el gremio de los profesionales de la disciplina habrá crecido y, quiérase o no, se convertirán muy probablemente en interlocutores racionales de los políticos de cualquier signo ideológico y de las organizaciones e instituciones políticas. En estas condiciones, el debate político va a recurrir al arsenal de ideas y planteamientos provenientes de la ciencia política contemporánea. Lo que se afirma no quiere decir que el debate político se desapasione. Esto sería imposible puesto que el debate político se alimenta de la "pasión" política, los "ánimos se caldean". Lo que se quiere decir es más bien que un interlocutor nuevo entrará en escena. Un interlocutor politólogo que ya sea como "participante" o ya sea como "observador" ha de recurrir a su acervo de conocimientos y herramientas científicas (la racionalidad científica) para analizar los temas de la agenda política; para tratar de influir en alguna dirección en su tratamiento; en fin, para poner racionalidad a la pasión.

\section{REFERENCIAS}

Alcántara Sáez, Manuel y Flavia Freidenberg (eds.). 2001. Partidos políticos de América Latina. Salamanca, España: Ediciones Universidad de Salamanca.

Artiga-González, Álvaro. 2004. Elitismo competitivo. San Salvador, El Salvador: UCA editores.

Artiga-González, Álvaro, Carlos Guillermo Ramos y Roberto Turcios. 2002. Más allá de las elecciones. San Salvador, EI Salvador: FLACSO-Programa El Salvador.

CAPEL. 2004. Democratización interna de partidos políticos en Centroamérica: avances y tareas pendientes. San J osé, Costa Rica: IIDH-CAPEL.

Cardenal, Rodolfo y Luis Armando González. 2002. La transición y sus problemas. San Salvador, El Salvador: UCA editores.

Córdova Macías, Ricardo y J osé Miguel Cruz. 2005. La cultura política de la democracia en El Salvador, 2004. San Salvador, El Salvador: USAID Misión El Salvador.

Cruz, José Miguel. 2001. ¿Elecciones para qué?: el impacto del ciclo electoral 1999-2000 en la cultura política salvadoreña. San Salvador, El Salvador: FLACSO-Programa El Salvador.

Guido Béjar, Rafael y Stefan Roggenbuck (eds.). 1996. Partidos y actores políticos en transición: la derecha, la izquierda y el centro en El Salvador. San Salvador, El Salvador: Konrad Adenauer Stiftung y Univesidad Centroamericana de EI Salvador.

Martínez, Rafael. 2004. La elección presidencial mediante doble vuelta en Latinoamérica. Barcelona: Institut de Ciencias Polítiques i Socials.

Mayorga Quirós, Román. 1976. La universidad para el cambio social. San Salvador: UCA editores.

Rovira Mas, Jorge (ed.). 2001. La democracia de Costa Rica ante el siglo XXI. San J osé, Costa Rica: Editorial de la Universidad de Costa Rica.

Santacruz Giralt, María. 2003. Una aproximación al estudio sobre las clases medias y su comportamiento político. San Salvador, El Salvador: Instituto Universitario de Opinión Pública (IUDOP).

Álvaro Artiga-González es sociólogo y politólogo centroamericano de origen salvadoreño. Actualmente, es Director del Programa de Maestría en Ciencia Política de la Universidad Centroamericana J osé Simeón Cañas (UCA) de El Salvador. (E-mail: alvart@buho.uca.edu.sv ) 